\title{
Performance analysis and simulation of a new industrial semi-active damper
}

\author{
S. Aubouet ${ }^{1 * *}$ O. Sename ${ }^{2 *}$ B. Talon ${ }^{* *}$ C. Poussot-Vassal ${ }^{*}$ \\ L. Dugard* \\ * GIPSA-lab, Control Systems Departement (former LAG), \\ INPG-CNRS-ENSIEG - Domaine Universitaire \\ BP46, 38402 Saint Martin d'Hères - Cedex FRANCE \\ ** SOBEN S.A.S., Pôle Mécanique d'Alès Cévenes, Vallon de \\ Fontanes, 30520 St-Martin de Valgalgues, FRANCE
}

\begin{abstract}
This paper deals with modeling and control of a semi-active suspension made up with a new industrial semi-active damper, in order to improve comfort and road-holding level of the vehicle. In the past few years, many control strategies have been developed using linear suspension models. A nonlinear model of the industrial damper is developed with physical equations and integrated in a quarter vehicle model. Some tests are done on the real damper in order to validate the model. The comfort and road-holding level of the semi-active suspension are studied using some adapted criteria and compared to the passive ones using simulations. These results emphasize the performances improvement resulting from the control of the damper.
\end{abstract}

\section{INTRODUCTION}

The main role of suspensions is to improve comfort by isolating the vehicle chassis to an uneven ground and to provide a good road-holding to ensure the safety of the passengers, especially during a bend. Suspension control based on quarter vehicle have been widely explored in the past few years to improve vertical movements either by applying Skyhook (Sammier et al., 2003; Choia et al., 2000), $\mathcal{H}_{\infty}$ control (Gaspar et al., 2004), LPV (Fialho and Balas, 2002) or mixed synthesis (Abdellahi et al., 2000; Takahashi et al., 1998), model-predictive techniques (Canale et al., 2006), using a mix one sensor control strategy (Savaresi and Spelta, 2007). Performance limitations of quarter-car active suspension models have also been studied (Türkay and Akçay, 2007). Semi-active suspensions are very interesting because of their low energy consumption compared to active ones and their high performances compared to passive ones.

The contribution of this paper is first to propose a nonlinear model of a new industrial damper, based on hydraulic laws, and integrate it in a quarter vehicle model. Then the study is focused on comfort and road-holding in the passive case, without controlling the damper, and in the semiactive case, controlling the damper with the well known Skyhook control law.

The paper is organized as follow: Section 2 introduces the different suspension types and describes SOBEN damper, Section 3 gives the architecture of the nonlinear model of the damper and the hydraulic equations that describe the damper's working. Section 4 deals with modeling a quarter vehicle in order to evaluate the performances of the vehicle. Different methods are used to define and evaluate these performances in Section 5. Then, a method to control

1 sebastien.aubouet@soben.fr

2 olivier.sename@inpg.fr the adjustments of the damper is developed in Section 6 , using a Skyhook control strategy. This practical method is used in Section 7 and some simulation results are given and show the interest of semi-active suspensions compared with passive ones. Section 8 concludes this paper and gives some possible future works.

\section{PRESENTATION OF THE TECHNOLOGY}

\subsection{SOBEN damper}

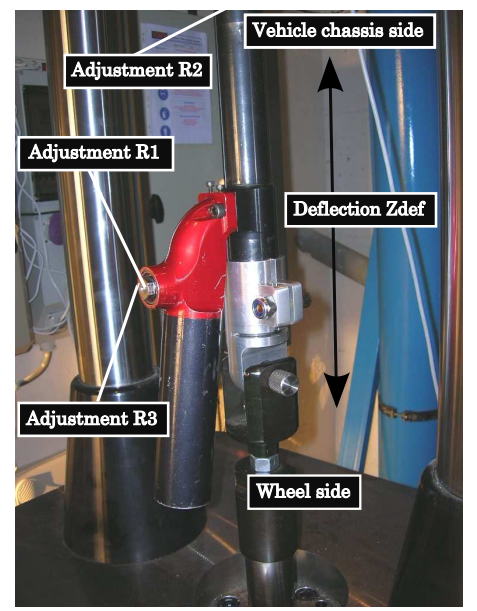

Fig. 1. SOBEN damper

There are three different types of suspensions (Zin, 2005). Both passive and semi-active suspensions are only able to dissipate energy but the way semi-active ones dissipate the energy depends on an external signal that is used to control the suspension, whereas passive suspensions are not adjustable. Active suspensions are both able to dissipate and provide energy and can be controlled. We consider here a semi-active damper, designed and built 
by SOBEN, that dissipates energy according to three adjustment parameters (Figure 1).

The innovative architecture of this damper allows the damper to provide a force as soon as it is prompted, without any delay. This ensures a very good chassis holding. Furthermore, there are many different oil circuits where the circulation depends on the speed and working phase: compression or release. Some adjustment parameters for each working phase allow the force provided by the damper to be controlled and avoid the force to increase too much in high speeds. Figure 2 presents the "Forcespeed diagram", commonly used to evaluate the characteristics of a damper. Three different types of technologies are presented. SOBEN and Concurrent 1 efforts increase quickly and ensure a good chassis holding, but Concurrent 1 effort increases too much when the speed increases and the vehicle becomes uncomfortable. On the other hand, Concurrent 2 effort increases very slowly when the speed increases: the vehicle is comfortable but behaves as a ship.

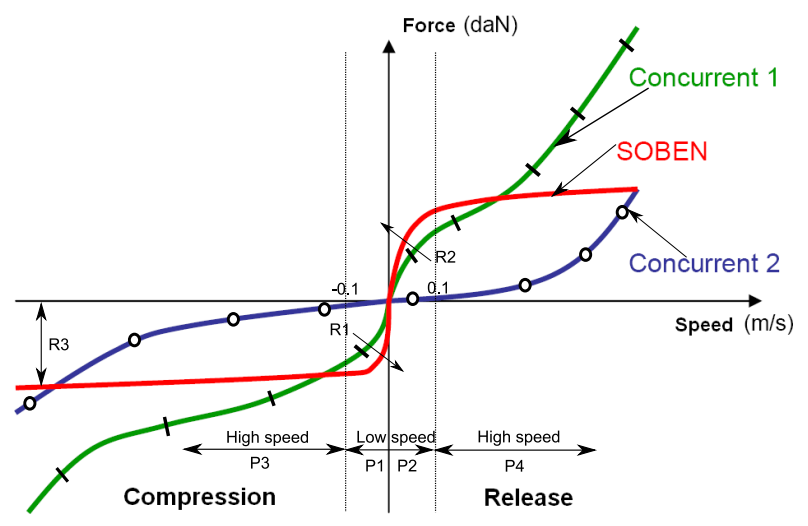

Fig. 2. Force-speed diagram for three damper types.

The force provided by SOBEN damper can be adjusted in phase $P 1, P 2$ and $P 3$ by changing $R 1, R 2$ and $R 3$ according to some mechanical or hydraulic parameters. $R 1$ and $R 2$ adjust the slope of the force-speed diagram in compression and release when the speed is low. $R 3$ adjusts the value of the force level in compression when the speed is high. There is no adjustment parameter for phase $P 4$. These adjustment parameters are innovative and very interesting to control the damper and improve its passive performances and the controlled behaviour as well.

\subsection{Tests and characterization}

Different types of tests have been run to characterize the force range the damper can provide. A testing ground has been used to impose the damper some sinusoidal deflection profiles for different frequencies, amplitudes and values of the adjustment parameters. Figures 3 presents the Force-speed diagram obtained with a sinusoidal deflection (Amplitude $A=0.08 m$ - Frequency $f=1.5 \mathrm{~Hz}$ ) for different values of $R 1$ (Figure 3: a), $R 2$ (Figure 3: b) and $R 3$ (Figure $3: \mathrm{c}$ ). These results show that $R 1$ adjusts the force in compression between a set lower limit depending on the technology and an upper limit depending on $R 3$. $R 2$ adjusts the force in release as $R 1$ in compression.

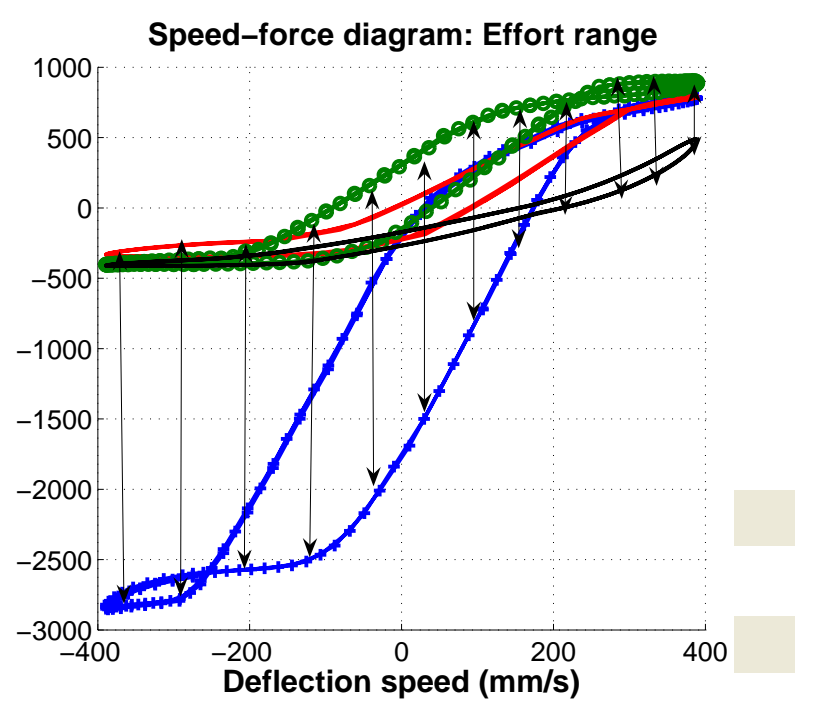

Fig. 4. Damper SOBEN: Effort range

The influence of $R 1, R 2$ and $R 3$ gives the effort range that the damper can provide for this deflection profile. This effort range is not absolute because the system is nonlinear. But the speed range studied here is the most interesting for a suspension. The maximal effort is obtained in compression for $R 1$ minimal and $R 3$ maximal, and vice versa. In release, the maximal effort is obtained with $R 2$ minimal. Figure 4 presents the force range the damper can provide thanks its adjustments.

\section{MODEL OF THE DAMPER}

\subsection{Presentation}

A physical nonlinear model of the damper is here developed to study the performances of the passive and controlled damper in the next sections. On the basis of equations describing the hydraulics of the damper, a complete model has been built, including each of the following elements: the compression, hydraulic stop, release and compensation chambers and the three adjustments of the damper. All these elements are coupled subsystems that exchange oil flows. Each element is described by its pressure and its volume. To build a model of such a complex system, the following simplifying hypothesis are done: the influence of the temperature is negligible, the compressibility of the oil is constant, bumps in the different oil circuits are negligible. Figure 5 presents the different elements of the damper and the interconnection where $z_{\text {def }}$ is the deflection of the suspension.

\subsection{Hydraulic equations}

The pressure $P_{i}$ in each chamber (Figure 5) and the oil flow $Q_{i}$ entering a chamber $i$, which volume is $V_{i}$, are given by Equation (1). $K$ is a compressibility constant, $\rho$ the density and $P_{i-1}$ the pressure in the chamber uphill.

$$
\left\{\begin{array}{c}
\dot{P}_{i}=\frac{\left(Q_{i}-\dot{V}_{i}\right) \cdot K}{V_{i}} \\
Q_{i}=\operatorname{sgn}\left(P_{i-1}-P_{i}\right) \cdot \sqrt{\frac{\left|P_{i-1}-P_{i}\right|}{\rho}} \cdot S_{d}
\end{array}\right.
$$

The model also includes many static maps identified with tests on the real damper and giving some nonlinear sections ( $S_{d}$ for example) where the oil flows in the damper. 

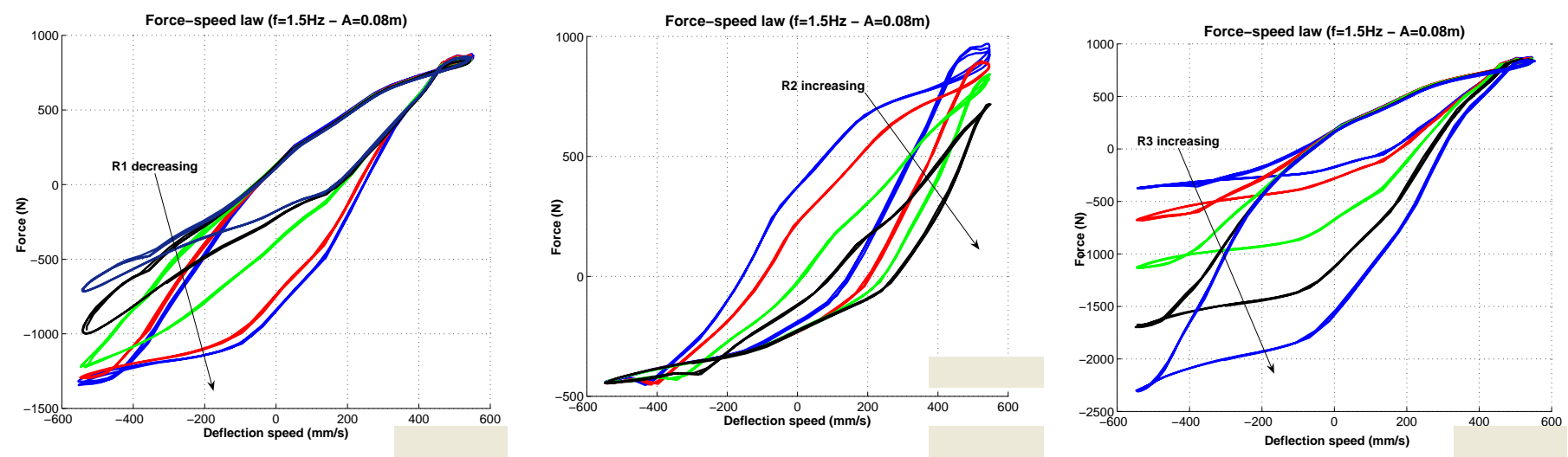

Fig. 3. Force-speed diagram: Influence of $R 1$ : a (left), $R 2$ : b (middle) and $R 3$ : c (right)

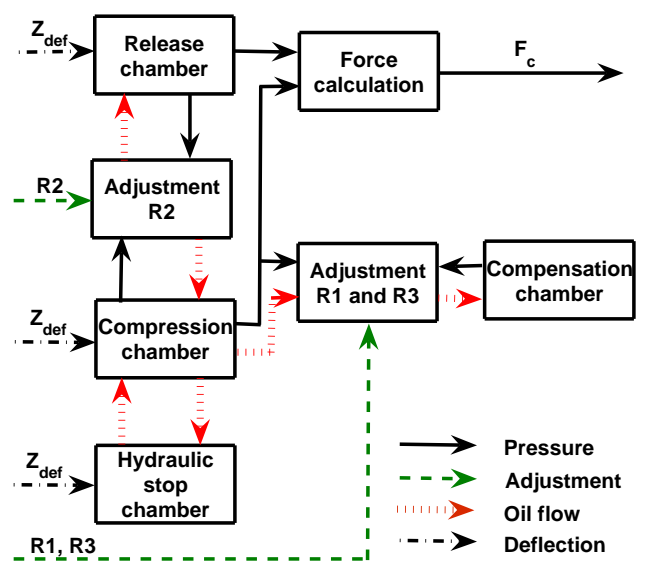

Fig. 5. Diagram of the model

These sections depend on the adjustment parameters and the geometry of many mechanical elements. These maps have been established with measurements. The model is able to compute the instantaneous pressures $P_{1}$ in the release chamber and $P_{2}$ in the compression chamber. The force $F_{c}$ provided by the damper is then computed (Figure $5)$ with equation (2). $S_{\text {piston }}$ is the section of the piston in the damper and $S_{\text {rod }}$ the section of the piston's rod.

$$
F_{c}=S_{\text {piston }} \cdot\left(P_{1}-P_{2}\right)+P_{2} \cdot S_{\text {rod }}
$$

Thus, the model computes the force the damper provides, from the following inputs: the deflection and the three adjustment parameters $R 1, R 2$ and $R 3$.

\subsection{Results and comparison}

Some tests on the real damper have been done. In this section, we compare measurements to simulations using the force-speed diagrams obtained for a sinusoidal deflection (Amplitude $A=0.08 m$ - Frequency $f=1.5 \mathrm{~Hz}$ ) for different values of $R 1, R 2$ and $R 3$. Figure 6 presents the results obtained for three different values of $R 1$. Thereby, the comparison has to be done only in compression (negative deflection speed).

These results show that simulations are quite similar to measurements, and the influence of the parameter $R 1$ on the behavior of the damper is coherent (Figure 2). However, the values of the force provided by the model
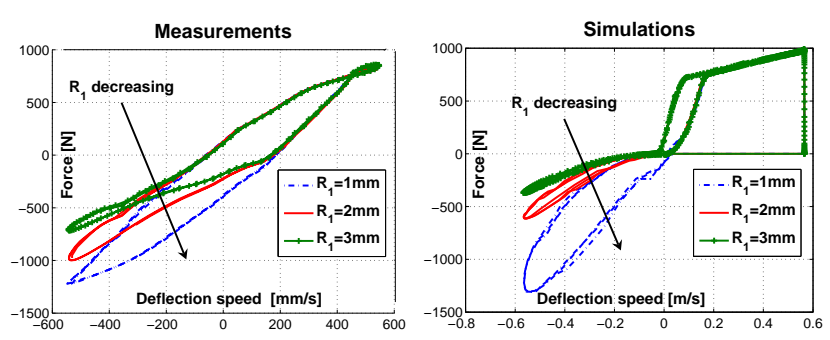

Fig. 6. Force-speed diagram: R1 varying

do not exactly correspond to the measured one because of the model approximation. There are indeed a lot a bumps in the oil circuits that cause pressure and force losses and that can not be modeled.

\section{QUARTER CAR MODEL}

This section aims at modeling a quarter vehicle model equipped with the damper, which is sufficient to study comfort and road-holding. The simplified quarter vehicle model (Zin, 2005; Sammier, 2001) involved here includes the sprung mass $\left(m_{s}\right)$ and the unsprung mass $\left(m_{u s}\right)$ and only catches vertical motions $\left(z_{s}, z_{u s}\right)$. As its damping coefficient is negligible, the tire is simply modeled by a spring $\left(F_{t}=k_{t}\left(z_{u s}-z_{r}\right)\right)$ linked to the $\operatorname{road}\left(z_{r}\right)$ where a contact point is assumed. The passive suspension, located between $m_{s}$ and $m_{u s}$ (Figure 7 ), is modeled by the damper (force $F_{c}$ ) and a spring $\left(F_{k}=k\left(z_{s}-z_{u s}\right)\right.$ ). The external force $F_{d z}$ on the sprung mass corresponds to a disturbance like a load transfer for example. The involved model parameters, that have been identified on a "Renault Mégane Coupé" (Zin et al., 2004) car, are given on Table 1.

\begin{tabular}{lll}
\hline Symbol & Value & Description \\
\hline$m_{s}$ & $315 \mathrm{~kg}$ & sprung mass \\
$m_{u s}$ & $37.5 \mathrm{~kg}$ & unsprung mass \\
$k$ & $29500 \mathrm{~N} / \mathrm{m}$ & suspension linearized stiffness \\
$c$ & $1500 \mathrm{~N} / \mathrm{m} / \mathrm{s}$ & suspension linearized damping \\
$k_{t}$ & $210000 \mathrm{~N} / \mathrm{m}$ & tire stiffness \\
\hline
\end{tabular}

Table 1. "Renault Mégane Coupé" parameters

$$
\begin{aligned}
m_{s} \ddot{z}_{s} & =k\left(z_{u s}-z_{s}\right)+F_{c} \\
m_{u s} \ddot{z}_{u s} & =k\left(z_{s}-z_{u s}\right)-F_{c}+k_{t}\left(z_{r}-z_{u s}\right)
\end{aligned}
$$




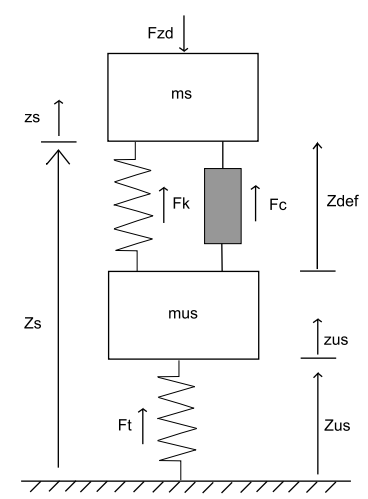

Fig. 7. Quarter car vehicle

The quarter car vehicle (Figure 7) is given by Equations (4) and describes the vertical motions of the two masses which is suitable to study both comfort and road-holding. This model is very useful to evaluate the performances and capabilities of dampers. The performances of the semiactive damper, which means controlled, are studied in Section 6 and compared to a passive reference damper corresponding to a set of parameters $R=(R 1, R 2, R 3)$ that makes SOBEN damper equivalent to the damper of the "Renault Mégane Coupé". $\left(F_{c}=c \dot{z}_{\text {def }}\right.$ with $c=1500$ $\mathrm{N} / \mathrm{m} / \mathrm{s}$ ). Figure 8 gives the force-speed diagram of these two dampers. Thereby SOBEN damper can be adjusted to have a similar behavior to Renault damper's one.

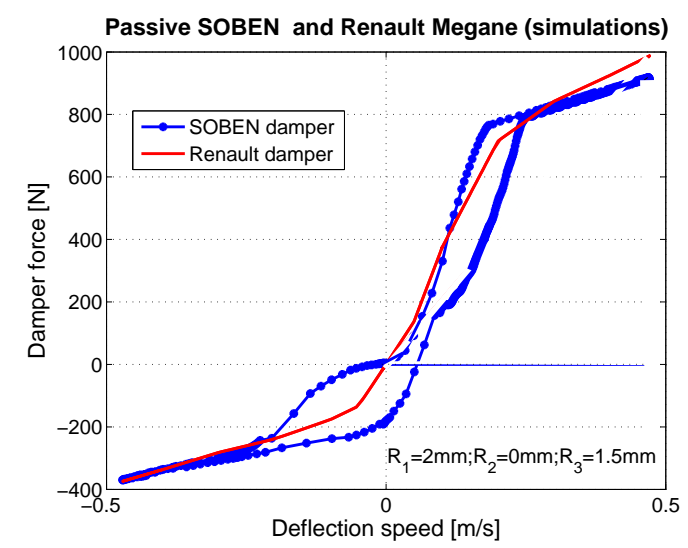

Fig. 8. Speed-Force diagram for two equivalent dampers

\section{COMFORT AND ROAD-HOLDING ANALYSIS}

The performances of the quarter vehicle can be evaluated studying the four following nonlinear input-output relations (Sammier, 2001; Zin, 2005): $z_{s} / z_{r}$ (comfort at low frequencies), $\ddot{z}_{s} / z_{r}$ (comfort at high frequencies), $z_{u s} / z_{r}$ and $z_{\text {def }} / z_{r}$ (road-holding and suspension constraint). The following criterion (Sammier, 2001) has been used for a function $g(f)$ depending on the frequency: $\int_{f_{1}}^{f_{2}} g(f)^{2} d f$. The gain of the four relations has to be minimized and the PSD criterion applied to these relations is a mean to evaluate their gain on the interesting frequency ranges, therefore it is a mean to evaluate comfort and roadholding. The frequency response (Poussot-Vassal et al., 2006) of the four relations has been plotted (Figure 9) in the passive case, with a sinusoidal input $z_{r}$ of varying magnitude (from $1 \mathrm{~cm}$ to $3 \mathrm{~cm}$ ) with varying frequencies (from $0.1 \mathrm{~Hz}$ to $20 \mathrm{~Hz}$ ). Each transfer has to be minimized to improve the performances, but there are some invariant behaviors (Zin, 2005). (CD) indicates a desired behavior, (PI) an invariant point in the plot and (AI) an invariant asymptote.
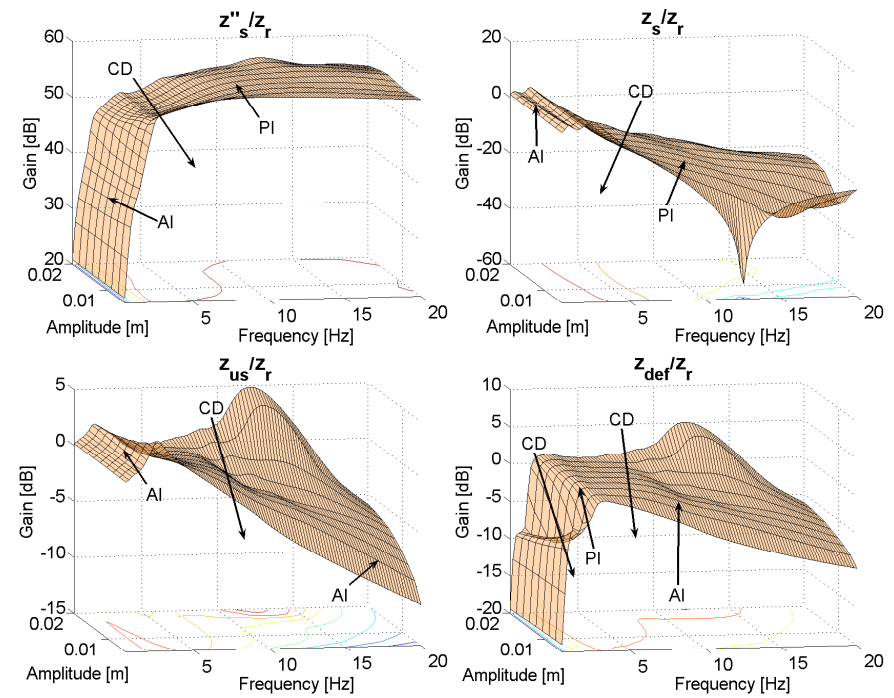

Fig. 9. Pseudo-Bode diagrams - Passive case

\section{TOWARDS THE CONTROL ARCHITECTURE OF THE NEW DAMPER}

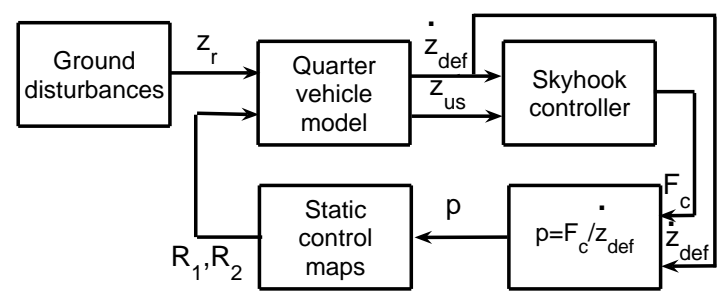

Fig. 10. Control strategy

Figure 10 presents the control architecture that has been developed to control the model of the new damper, using two static maps. A simple Skyhook control strategy has been chosen to illustrate this methodology. The well known suspension oriented Skyhook control algorithm (Sammier, 2001; Poussot-Vassal et al., 2006) consists in designing an active suspension control so that the chassis is linked to the sky by a damper in order to reduce vertical oscillations of the chassis and of the axle independently. Using this control strategy, the approximated Skyhook force has been chosen (Sammier, 2001): $F_{c}=-c_{s k y} \dot{z}_{s}+\alpha c_{s k y} \dot{z}_{u s}\left(c_{s k y}>\right.$ 0 and $\alpha \in[0 ; 1]$ are design parameters that influence the performances).

If the damper is controlled, this computed force $F_{c}$ should be provided by the damper to improve the performances of the quarter car model. The force $F_{m}$ indeed provided by the damper depends both on the adjustment parameters and the deflection speed: $F_{m}=f\left(R 1, R 2, \dot{z}_{\text {def }}\right)$, thereby the adjustment parameters have to be determined and applied on line to control the damper. The methodology 
presented in this paper to control the damper is based on a static map that gives $(R 1, R 2)$ to provide the force $F_{c}$ when the deflection speed is $\dot{z}_{\text {def }}$ :

Step 1: Do measurements to get the static map $F_{m}=$ $f\left(R 1, R 2, \dot{z}_{d e f}\right)$ :

- Excite the damper with a sinusoidal displacement and save the force $F_{m}$ provided by the damper and $v_{m}$ its displacement speed,

- Repeat previous step with varying $R 1$ and $R 2$,

- Plot the force-speed diagrams for each adjustment parameters $R 1$ and $R 2$.

The static three-dimensional map obtained here (with measurements or simulations) can be saved in the controller and performed on line to determine the adjustment parameters. This solution requires a lot of memory if the map is accurate. A method to get a simplified static map on the basis of the previous one is proposed here:

Step 2: Compute simplified two dimensional map:

- Identify the force-speed diagrams with the following chosen formula: $F_{m}=p v_{m}^{2}$ where $p$ is the parameter to identify,

- Compute the parameter $p$ minimizing the criteria $J=\left\|p \cdot v_{m}^{2}-F_{m}\right\|^{2}$ so that $F_{m}=p v_{m}^{2}$ is a good approximation of the force-speed diagram,

- Get a parameter $p_{1}$ for each adjustment parameter of the damper in compression and $p_{2}$ in release,

- Plot the identified and measured speed-force diagrams (Figure 11).

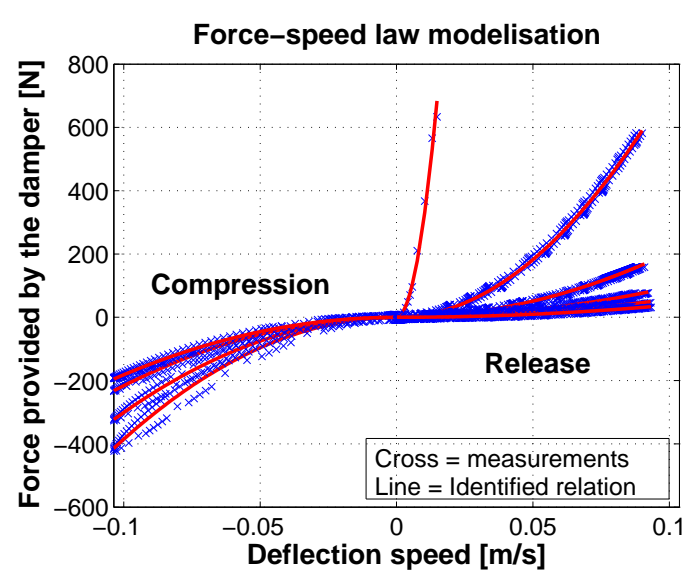

Fig. 11. Force-speed diagram identification with $F_{m}=p v_{m}^{2}$

Here the objective is to do some simulations of the controlled damper model, hence the static maps have been determined using the model. (Figure 12)

Step 3: Use for on-line control:

- $p_{i}$ is computed on line with the equation $p_{i}=F_{m} / v_{m}^{2}$,

- The two maps (Figure 12) give $R 1$ and $R 2$,

- $R 1$ and $R 2$ allow the damper to provide the desired force $u=F_{c}$.

\section{RESULTS}

Some simulations have been done using the control scheme above. Time responses to a ground disturbance (magni-
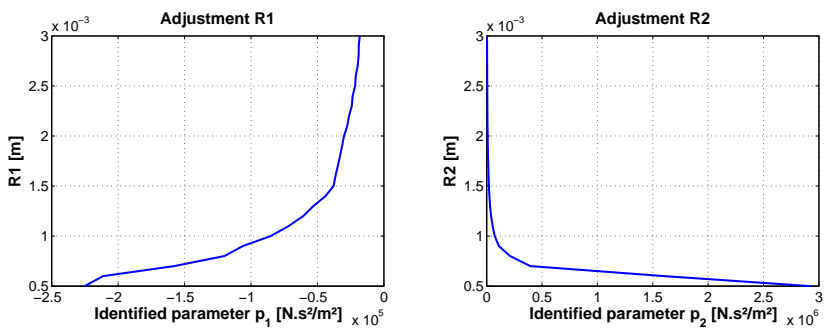

Fig. 12. Control tables: compression and release

tude $2 \mathrm{~cm}$ ) are shown. Figure 13 presents the position of the chassis (left) and the deflection (right).

Parameters $\left(\alpha, c_{s k y}\right)_{\text {comfort }}=(0.2,5000)$ have been chosen to give more importance to comfort than road-holding whereas parameters $\left(\alpha, c_{s k y}\right)_{\text {rhold }}=(0.8,5000)$ give more importance to road-holding. The semi-active results obtained using these control parameters are compared with those obtained with the passive reference suspension. The position of the chassis gives information on the comfort and the deflection of the suspension gives information on road-holding. These results (Figure 13), compared to the passive case, show that the two configurations of the Skyhook improve comfort $\left(\left(\alpha, c_{s k y}\right)_{\text {comfort }}\right)$ and road-holding $\left(\left(\alpha, c_{s k y}\right)_{\text {rhold }}\right)$. However, both comfort and road-holding are difficult to evaluate with temporal results. To study the influence of the parameters $\alpha$ and $c_{s k y}$ on $\ddot{z}_{s} / z_{r}, z_{s} / z_{r}$, $z_{u s} / z_{r}$ and $z_{\text {def } f} / z_{r}$, the PSD criterion for many values of $\left(\alpha, c_{s k y}\right)$ (Figure 14) has been computed:
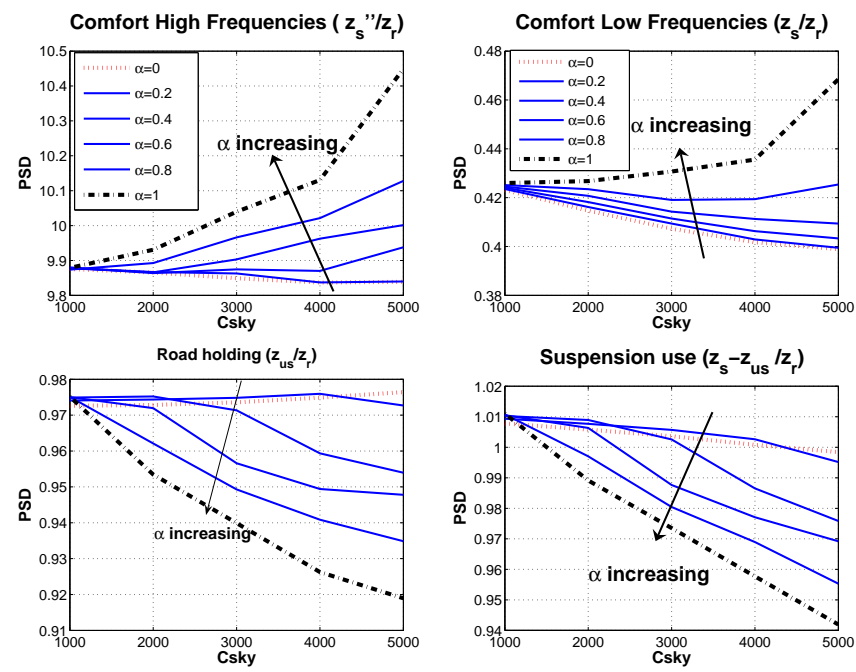

Fig. 14. Influence of $\alpha$ and $c_{s k y}$

If $\alpha=1$, there is no damper between the chassis and the sky, thereby the suspension is passive with a damping coefficient $c_{s k y}$. This case, compared to the others illustrates the influence of the control strategy on the performances of the damper. The following conclusions can be drown from these results (Figure 14):

- Increasing $\alpha$ ( $c_{s k y}$ constant) improves road-holding and damages comfort,

- Increasing $c_{s k y}$ ( $\alpha$ constant) damages comfort and improves road-holding. 


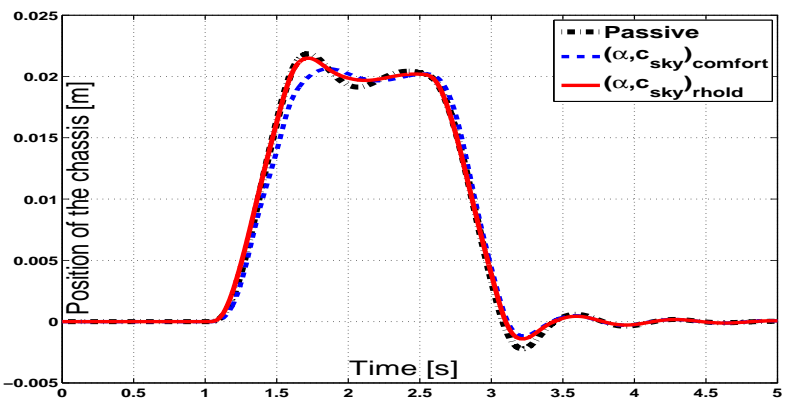

Fig. 13. Time response to a ground disturbance

Table 2 gives the PSD criteria for the Passive suspension $(\mathrm{P})$, Semi-Active suspension with parameters $\left(\alpha, c_{s k y}\right)_{\text {comfort }}\left(S A_{1}\right)$ and $\left(\alpha, c_{s k y}\right)_{\text {rhold }}\left(S A_{2}\right) . G_{1}$ and $G_{2}$ represent the improvement obtained controlling the suspension in relation with the passive case. Skyhook

\begin{tabular}{|l|l|l|l|l|l|}
\hline & $\mathrm{P}$ & $S A_{1}$ & $G_{1}$ & $S A_{2}$ & $G_{2}$ \\
\hline$\left.\ddot{z}_{s} / z_{r} f \in[0,5]\right]$ & 11.7 & 9.5 & $19 \%$ & 10.5 & $10 \%$ \\
\hline$\left.z_{s} / z_{r} f \in[0,5]\right]$ & 0.56 & 0.38 & $32 \%$ & 0.47 & $16 \%$ \\
\hline$\left.z_{u s} / z_{r} f \in[0,20]\right]$ & 0.95 & 1.12 & $-17 \%$ & 0.92 & $3 \%$ \\
\hline$\left.z_{\text {def }} / z_{r} f \in[0,20]\right]$ & 0.95 & 1.19 & $-25 \%$ & 0.94 & $1 \%$ \\
\hline
\end{tabular}

Table 2. PSD criteria in passive and semiactive cases

control improves comfort $\left(\ddot{z}_{s} / z_{r}\right.$ and $\left.z_{s} / z_{r}\right)$ and not roadholding $\left(z_{u s} / z_{r}\right.$ and $\left.z_{\text {def }} / z_{r}\right)$ which is logical because the approximated Skyhook force only controls the motion of the chassis and not the motion of the wheel.

\section{CONCLUSION AND FUTURE WORKS}

The behavior of a new industrial damper has been studied using different kinds of tests. Then, a physical model was developed using hydraulic equations, and compared to measurements. This physical and nonlinear model has been integrated in a quarter vehicle model. In order to improve the performances of the quarter vehicle model, some industrial criteria have been used to study comfort and road-holding. A control architecture has been proposed using the Skyhook methodology and including two static maps (identified from force-speed diagrams). The performances of the passive and semi-active suspensions have been simulated in time and frequency domains and emphasize the interest of controlled dampers. A simple control strategy (Skyhook) has been used here for illustration. More performant strategies are now under study. The next issue is to do real tests of the controlled damper which first requires performant actuators. In a future work, the damper nonlinear model will be integrated in a full car model in order to do a Global Chassis Control following the same methodology as developed in this work.

\section{REFERENCES}

E. Abdellahi, D. Mehdi, and M. M Saad. On the design of active suspension system by $\mathcal{H}_{\infty}$ and mixed $\mathcal{H}_{2} / \mathcal{H}_{\infty}$ : An LMI approach. In Proceedings of the American Control Conference, pages 4041-4045, Chicago, USA, june 2000.

M. Canale, M. Milanese, and C. Novara. Semi-active suspension control using "fast" model-predictive tech-

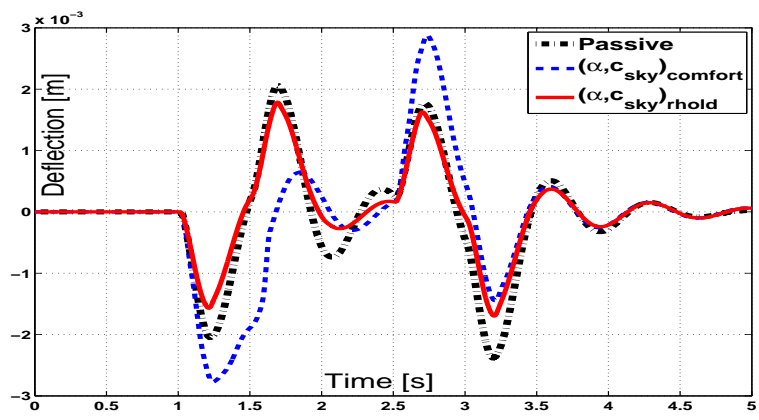

niques. In IEEE Transactions on control systems technology, vol.14, no.6, november 2006.

Choia, S-B., H.K. Leea, and E.G. Chang. Field test results of a semi-active suspension system associated with skyhook controller. Mechatronics, pages 11, 345353, 2000.

I. Fialho and G. Balas. Road adaptive active suspension design using linear parameter varying gain scheduling. In IEEE Transaction on Systems Technology, pages 10(1):43-54, january 2002.

P. Gaspar, I. Szaszi, and J. Bokor. Active suspension design using LPV control. In Proceedings of the 1st IFAC Symposium on Advances in Automotive Control, pages 584-589, Salerno, Italy, 2004.

C. Poussot-Vassal, O. Sename, L. Dugard, R. RamirezMendoza, and L. Flores. Optimal skyhook control for semi-active suspensions. In Proceedings of the 4th IFAC Symposium on Mechatronics Systems, pages 608-613, Heidelberg, Germany, september 2006.

D. Sammier. Sur la modélisation et la commande de suspensions de véhicules automobiles. Phd thesis, Institut National Polytechnique de Grenoble, 2001.

D. Sammier, O. Sename, and L. Dugard. Skyhook and $\mathcal{H}_{\infty}$ control of active vehicle suspensions: some practical aspects. Vehicle System Dynamics, pages 39(4):279-308, April 2003.

S. M. Savaresi and C. Spelta. Mix-1-sensor: A control strategy for semi-active suspensions. In Fifth IFAC Symposium on Advances in Automotive Control, Monterey Coast, California, USA, august 2007.

R.H.C. Takahashi, J.F. Camino, D.E. Zampieri, and P.L.D. Peres. A multiobjective approach for $\mathcal{H}_{2}$ and $\mathcal{H}_{\infty}$ active suspension control. In Proceedings of the American Control Conference, pages 48-52, Philadelphia, USA, june 1998.

S. Türkay and H. Akçay. On the prformance limitations of quarter-car active suspensions models. In Fifth IFAC Symposium on Advances in Automotive Control, Monterey Coast, California, USA, august 2007.

A. Zin. Sur la commande robuste de suspensions automobiles en vue du contôle global de chassis. Phd thesis, Institut National Polytechnique de Grenoble, 2005.

A. Zin, O. Sename, M. Basset, L. Dugard, and G. Gissinger. A nonlinear vehicle bicycle model for suspension and handling control studies. In Proceedings of the IFAC Conference on Advances in Vehicle Control and Safety (AVCS), pages 638-643, Genova, Italy, october 2004. 